\title{
Progresso da cercosporiose em diferentes genótipos de beterraba
}

\author{
Leandro Luiz Marcuzzo ${ }^{1}$, Tatiana da Silva Duarte $^{2} \odot$
}

${ }^{1}$ Instituto Federal Catarinense - IFC/Campus Rio do Sul, CP 441, CEP 89.163-356, Rio do Sul-SC, Brasil. ${ }^{2}$ Universidade Federal do Rio Grande do Sul - UFRGS, Faculdade de Agronomia, Departamento de horticultura e silvicultura, CP 15.100, CEP 91540-000, Porto Alegre-RS, Brasil.

Autor para correspondência: Leandro Luiz Marcuzzo (leandro.marcuzzo@ifc.edu.br)

Data de chegada: 11/02/2019. Aceito para publicação em: 19/12/2019.

$10.1590 / 0100-5405 / 219773$

A cercosporiose da beterraba causado por Cercospora beticola Saac. é a principal doença da cultura por causar a destruição a área foliar e redução na produção (5). Sua ocorrência generalizada pode representar redução de $15 \%$ a $45 \%$ a produtividade, em condições de alta umidade relativa do ar, maior que $90 \%$, e temperatura entre 22 e $26^{\circ} \mathrm{C}(10)$. Os sintomas são manchas circulares com bordos de cor purpúrea e centro claro e, à medida que aumentam, tornam-se com tonalidade acinzentadas. A necrose do tecido lesionado cai e a folha torna-se perfurada (7). O uso de genótipos resistentes é uma das formas de manejo dessa doença, porém é necessária a avaliação do comportamento temporal da doença entre genótipos. Entre as formas de caracterizar o crescimento temporal de epidemias, a curva de progresso temporal é a que melhor representa uma epidemia. A interpretação do formato dessas curvas e seus componentes, como a taxa e a severidade final podem ser usadas para determinar o progresso da doença em genótipos (2,3). O objetivo deste trabalho foi caracterizar o progresso temporal da cercosporiose em diferentes genótipos de beterraba. $\mathrm{O}$ experimento foi conduzido entre 30 de novembro de 2012 a 20 de fevereiro de 2013 na Epagri/Estação Experimental de Ituporanga, localizada no município de Ituporanga, região do Alto Vale do Itajaí em Santa Catarina. As coordenadas geográficas são de latitude de $27^{\circ} 38^{\prime} \mathrm{S}$, longitude de $49^{\circ} 60^{\prime} \mathrm{W}$ e altitude de 475 metros acima do nível do mar. Utilizaram-se sete diferentes genótipos de beterraba, os mais utilizados pelos agricultores na região, para caracterização do progresso da cercosporiose: All Green, Stays Green, Early Wonder Tall Top, Cabernet (híbrido), Boro (híbrido), Modana (monogérmica) e Itapuã. $\mathrm{O}$ delineamento experimental foi em blocos casualizados com quatro repetições. A semeadura foi realizada manualmente, sendo que cada unidade experimental continha 2,25 $\mathrm{m}^{2}(1,5 \mathrm{~m} \times 1,5 \mathrm{~m})$, dividida em 5 linhas com espaçamento de $30 \mathrm{~cm}$ entre linhas e $10 \mathrm{~cm}$ entre plantas, contendo um total de 75 plantas. O inóculo do patógeno proveniente da disseminação pelo vento, de plantas com sintomas da doença em outro experimento conduzido na mesma área e semanalmente, após a semeadura, foi avaliada a severidade da cercosporiose nas folhas expandidas em dez plantas demarcadas aleatoriamente com auxílio de escala diagramática proposta por May de Mio et al. (8) a intervalos regulares de sete dias. A colheita das plantas demarcadas foi realizada quando as plantas atingiram um período de 82 dias após a semeadura, tendo as raízes sido pesadas e posteriormente convertidas para produtividade em Kilogramas por hectare $\left(\mathrm{Kg}_{\mathrm{h}} \mathrm{ha}^{-1}\right)$. Modelos não lineares, comumente usados para representar crescimento de epidemias como o Logístico e o de Gompertz foram usados para ajuste com os dados observados utilizando o software R versão 2.15.1(9). Os critérios estabelecidos para comparação dos modelos, em função da qualidade do ajustamento dos dados foram: a) erro padrão da estimativa; b) estabilidade dos parâmetros; c) erro padrão dos resíduos; d) visualização da distribuição dos resíduos ao longo do tempo e e) pseudo $\mathrm{R}^{2}$. Os dados da taxa e da produtividade $\left(\mathrm{Kg}_{\mathrm{g}} \mathrm{ha}^{-1}\right)$ foram submetidos à análise estatística ao nível de 5\% pelo software estatístico SASM-Agri (4) para avaliar os efeitos entre os genótipos. O modelo de Gompertz expresso por $\mathrm{y}=\operatorname{ymax} *(\exp (-\ln (\mathrm{y} 0 / \mathrm{ymax}) * \exp (-\mathrm{r} * \mathrm{x})))$, onde $\mathrm{y}$ : severidade estimada final (\% de severidade/100); ymax: severidade máxima de doença/100; $\ln (\mathrm{y} 0 / \mathrm{ymax})$ refere-se a função de proporção da doença na primeira observação; r: taxa,x o tempo em semanas após o inicio da doença foi escolhido para representar o progresso da cercosporiose na avaliação dos genótipos de beterraba (Tabela 1). Possivelmente

Tabela 1. Produtividade (kg.ha ${ }^{-1}$ ) e os parâmetros estimados pelo modelo de Gompertz ajustado aos dados de severidade da cercosporiose em diferentes genótipos de beterraba. EPAGRI, E.E. Ituporanga, 2012/2013

\begin{tabular}{lccccc}
\hline \multirow{2}{*}{ Genótipo } & \multicolumn{2}{c}{ Parâmetros do modelo de Gompertz* } & \multicolumn{2}{c}{$\begin{array}{c}\text { Produtividade } \\
\left(\mathbf{K g}^{*} \mathbf{h a}^{-1}\right)\end{array}$} \\
\cline { 2 - 5 } Boro & $\mathbf{y m a x}$ & $\mathbf{l n}(\mathbf{y} \mathbf{0} / \mathbf{y m a x})$ & $\mathbf{r}$ & $\boldsymbol{R}^{2}$ & $12.648 \mathrm{~ns} * *$ \\
Stays Green & 0,201406 & 24,776398 & $0,857317 \mathrm{~ns}^{* *}$ & 0,9986429 & 17.007 \\
Modana & 0,185985 & 20,308722 & 0,820397 & 0,9987991 & 16.194 \\
All Green & 0,19486 & 24,29672 & 0,837030 & 0,998940 & 16.554 \\
Early Wonder & 0,206912 & 13,220800 & 0,818888 & 0,9991348 & 15.510 \\
Cabernet & 0,197903 & 16,022365 & 0,917997 & 0,9970341 & 12.467 \\
Itapuã & 0,186593 & 24,658725 & 0,928598 & 0,9968007 & 10.892 \\
\hline CV (\%) & 0,18789 & 20,75248 & 0,822380 & 0,9986277 & 34,05
\end{tabular}

*y=ymax * $(\exp (-\ln (\mathrm{y} 0 / \mathrm{ymax}) * \exp (-\mathrm{r} * \mathrm{x})))$. onde $\mathrm{y}$ : severidade estimada final (\% de severidade/100); ymax: severidade máxima de doença/100; $\ln (\mathrm{y} 0 / \mathrm{ymax})$ refere-se a função de proporção da doença na primeira observação; r: taxa. x o tempo em semanas e $R^{2}$ coeficiente de determinação. ** ns - não significativo pelo teste F 5\%. 

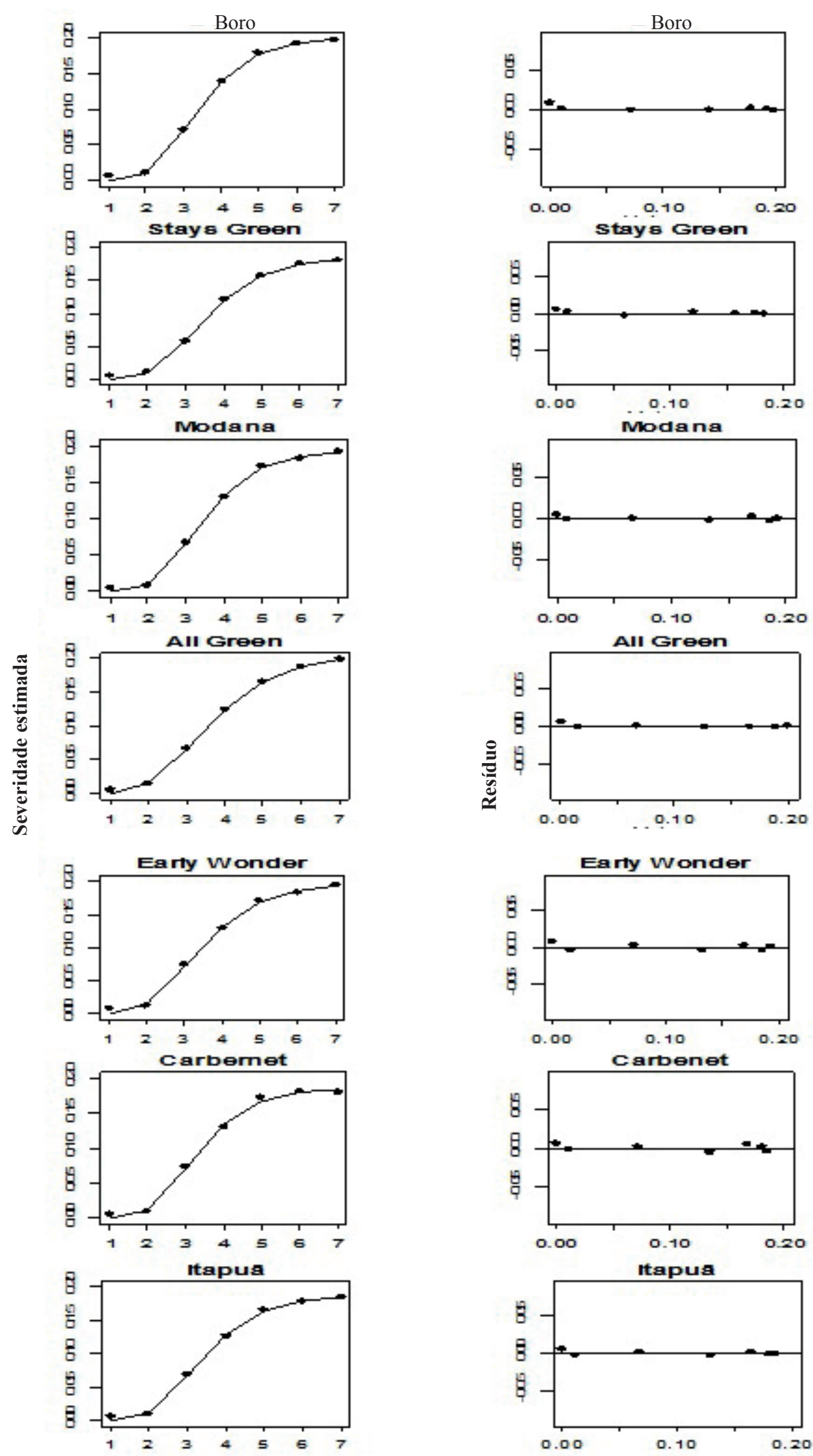

Semanas após o início da doença

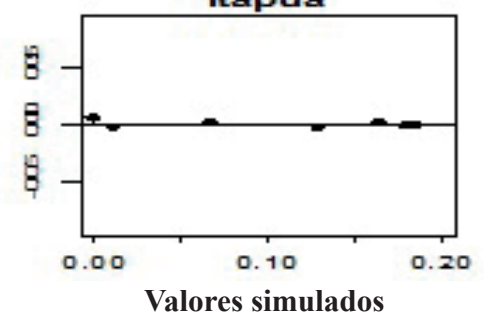

Figura 1. Curva da severidade estimada do progresso da cercoporiose em diferentes genótipos de beterraba e seus respectivos resíduos ajustados pelo modelo de Gompertz. E.E. Ituporanga. 2012/2013. 
todos os dados se ajustaram em decorrência de ser a época de cultivo da cultura e a presença da doença na região. A análise dos dados e as equações originadas pelo modelo de Gompertz (Tabela 1) resultaram em um coeficiente de determinação significativo, e a severidade observada correspondeu ao modelo, confirmada pela coerência entre os pontos estimados e do resíduo (erro) nas sete semanas de avaliação (Figura 1). No presente trabalho, a detecção da cercosporiose foi registrada na quinta semana em todos os cultivares com $0,41 \%$ e seguiu de forma acentuada até a sétima primeira As curvas progrediram de forma similar (Figura 1), pois não se observa diferenças marcantes entre o comportamento do progresso da doença entre os cultivares, fato esse comprovado pela severidade final e taxa (Tabela 1). A taxa de progresso da doença não diferiu estatisticamente entre os genótipos (Tabela 1). Foi verificado que o genótipo Carbenet apresentou a maior taxa $(0,928)$ de progresso, enquanto que All Green a menor $(0,818)$. Verificou-se que o genótipo All Green apresentou o pico máximo da severidade com $20,6 \%$ e que Stays Green teve o menor acúmulo da doença com $18,6 \%$ (Tabela 1). Em outros trabalhos realizados com beterraba açucareira (6) demonstraram que o genótipo suscetível apresentou uma severidade máxima de $15,62 \%$ enquanto para o genótipo suscetibilidade foi 5,66\% em cinco anos de avaliação. Bălău (1) constatou pequenas diferenças, entre 2,0 e 2,4 pontos percentuais na severidade máxima de três genótipos, semelhante aos resultados aqui apresentados. Kaiser et al. (7) avaliando o progresso da cercosporiose em diferentes genótipos de beterraba açucareira, constataram que na presença da doença os genótipos se comportaram de maneira semelhante. A produtividade $(\mathrm{Kg}$. $\mathrm{ha}^{-1}$ ) não diferiu entre os genótipos avaliados (Tabela 1). Na Lituânia, também não encontraram diferenças significativas $(\mathrm{P}<0,05 \%)$ para produtividade de beterraba açucareira afetada por cercosporiose (6). Também Bălău (1) na Romênia não verificou diferença de produtividade entre genótipos em diferentes anos de avaliação com a presença da doença. Embora não significativo, a cultivar mais produtiva (Stays Green) teve uma diferença de $64 \%$ na produtividade em relação a menos produtiva (Itapuã) (Tabela 1). Conclui-se que os genótipos avaliados não apresentaram diferença no comportamento de progresso quanto à cercosporiose, no entanto, o genótipo Stays Green apresentou a menor intensidade da doença, enquanto que All Green a maior, apesar de que a menor taxa foi verificada nesse genótipo.

\section{AGRADECIMENTOS}

Ao CNPq e à FAPESC (chamada pública do acordo de cooperação $\mathrm{CNPq}+\mathrm{FAPESC}$ - Repensa) pelo apoio financeiro recebido para condução deste trabalho e pela concessão de bolsas ATP - B.

\section{REFERÊNCIAS}

1. Bălău, A.M. Research regarding the epidemic evolution of Cercospora leaf spot (Cercospora beticola Sacc.) under ezareni farm conditions. Lucrăriştiințifice, Timişoara, v. 54, n.2, p.199-202, 2011.

2. Bergamim Filho, A.; Amorim, L. Doenças de plantas tropicais: epidemiologia e controle econômico. São Paulo: Ceres, 1996, 289p.

3. Campbell, C.L.; Madden, L.V. Introduction to plant disease epidemiology. New York : Wiley Interscience, 1990. 532p.

4. Canteri, M.G.; Althaus, R.A.; Virgens Filho, J.S.; Giglioti, E.A.; Godoy, C.V. SASM - Agri: Sistema para análise e separação de médias em experimentos agrícolas pelos métodos Scoft - Knott, Tukey e Duncan. Revista Brasileira de Agrocomputação, Ponta Grossa, v.1, p.18-24, 2001.

5. Ferreira, M.D.; Tivelli, S.W. Cultura da beterraba: recomendações gerais. Guaxupé, Cooxupé, 1989, 14p. (Boletim Técnico, 2).

6. Gaurilčikienè, I.; Deveikytė, I.; Petraitienè, E. Epidemic progress of Cercospora beticola Sacc. in Beta vulgaris L. under different conditions and cultivar resistance. Biologija, Vilnius, v.4, p.54-59, 2006.

7. Kaiser, U.; Kluth, C.; Märländer, A. variety-specific epidemiology of Cercospora beticola Sacc. and consequences for threshold-based timing of fungicide application in sugar beet. Journal of Phytopathology, Berlin, v.158, n.4, p.296-306, 2010.

8. May de Mio, L.L.; Oliveira, R.A.; Floriani, A.M.V.; Schuber, J.M.; Poltronf ieri, A.S.; Araujo, M.A.; Tratch, R. Proposta de escala diagramática para quantificação da cercosporiose da beterraba. Scientia Agraria, Curitiba, v.9, n.3, p.331-337, 2008.

9. R Development Core Team (2012). R: A language and environment for statistical computing. R Foundation for Statistical Computing, Vienna, Austria. Disponível em: $<\mathrm{http}$ ///www.R-project.org $>$. Acesso em: 15 nov. 2018.

10. Tivelli, S.W; Factor, T.L.; Teramoto, J.R.S.; Fahi, E.G.; Moraes, A.R.A.; Trani, P.E.; May, A. Beterraba, do plantio à comercialização. Série Tecnologia APTA. Boletim Técnico IAC, 210. Campinas: Instituto Agronômico. 2011, 45p. 